\title{
Anti-tumor action of tumor necrosis factor against Bomirski Ab melanoma in hamsters
}

\author{
Patrycja Koszałka $^{1}$, Ewa Szmit ${ }^{2}$, Andrzej Myśliwski ${ }^{2}$ and Jacek Bigda ${ }^{1}$ \\ ${ }^{1}$ Department of Medical Biotechnology, Division of Cell Biology, Intercollegiate Faculty of Biotechnology, \\ Medical University of Gdańsk, Gdańsk, Poland \\ ${ }^{2}$ Department of Histology and Immunology, Medical University of Gdańsk, Gdańsk, Poland
}

Received: 2007.01.04, Accepted: 2007.05.27, Published online first: 2007.07.23

\begin{abstract}
Introduction: Tumor necrosis factor (TNF) is a cytokine able to exert anti-tumor activity in various models and modes of applications. However, the exact mechanism mediating the in vivo anti-tumor effect of TNF has not yet been clarified.

Materials and Methods: The effects of intratumoral injection of rat TNF into hamsters bearing Bomirski Ab amelanotic melanoma, a fast growing tumor of high metastatic potential, were tested. Subcutaneous injections of the anti-angiogenic compound TNP-470 allowed analysis of its influence on the effects of TNF administration.

Results: TNF application resulted in a significant inhibition of tumor growth and changes in metastasis pattern. Accelerated hemorrhagic necrosis was also observed, indicating the effect of the cytokine on tumor vessels. Moreover, the synergistic anti-tumor effect of TNF and anti-angiogenic agent TNP-470 suggested a cooperative activity of both substances on tumor vasculature. Microscopically, the effect of TNF injections was expressed by an increase in the amount of tumor cells with nuclear pyknosis and karryorrhexis. In vitro assays indicated a direct cytotoxic effect of TNF against Ab melanoma cells, most probably as an outcome of apoptosis. Intratumoral application of TNF also caused some modulation of cytokine response in melanoma-bearing hamsters as evidenced by increased levels of IL-6 in blood serum.

Conclusions: This study established Bomirski Ab melanoma as a useful model for complex analysis of the anti-tumor activity of TNF.

Key words: TNF, melanoma, tumor vasculature, immune modulation.

Abbreviations: CTL - cytotoxic T lymphocytes, E. coli-Escherichia coli, FBS - fetal bovine serum, MTT - (3-[4,5-dimethylthiazol-2-yl]-2,5-diphenyltetrazolium bromide, NK - natural killer, TNF - tumor necrosis factor, TNP-470 - O-(Chloroacetyl-carbamoyl)fumagillol, BSA - bovine serum albumin, NO - nitric oxide, PBS - phosphate buffered saline.
\end{abstract}

Corresponding author: Patrycja Koszałka, Department of Medical Biotechnology, Division of Cell Biology, Intercollegiate Faculty of Biotechnology, Medical University of Gdańsk, Dębinki 1, 80-211 Gdańsk, Poland, e-mail: pkosz@amg.gda.pl

\section{INTRODUCTION}

Tumor necrosis factor (TNF, TNF- $\alpha$, cachectin) is a multifunctional cytokine produced mainly by activated macrophages and/or monocytes. It can also be produced by some tumor cell lines [35]. TNF occurs as a $26-\mathrm{kDa}$ transmembrane precursor form and as a $17-\mathrm{kDa}$ soluble mature form, which appears mainly as a homotrimer [62]. Mature TNF displays a high degree of homology in mammals [41, 72] and therefore its biological activity has limited species specificity [58].

TNF was firstly reported as a macrophage-derived serum factor that caused hemorrhagic necrosis of tumors [12]. Today, TNF is well-known as having a wide range of biological activities both in vitro and in vivo
[40]; for example, it affects the proliferation of normal cells, takes part in homeostasis regulation, inflammatory, immunoregulatory, and antiviral responses, and plays an important role in septic shock [2, 61, 63, 68]. TNF also exerts some cytotoxic and cytostatic effect on numerous tumor cell lines in vitro [51] and exhibits anti-tumor activity in some tumor models in vivo [20, 53]. Systemic treatment with TNF, however, is associated with severe side-effects, and this limits the clinical use of the cytokine in the therapy of melanomas mainly to the isolated limb perfusion regimen [18].

The exact mechanism mediating the in vivo anti-tumor effect of TNF has not been yet fully clarified. There are at least three possible ways in which TNF can exert anti-tumor activity: by direct cytostatic or cytotox- 
ic action on tumor cells, by its effect as a regulatory mediator of the host-mediated immunological response in neoplasia, and by augmenting hemorrhagic necrosis within a tumor by affecting its vasculature. Furthermore, cell sensitivity to the growth-inhibiting effect of TNF is influenced by other cytokines, hormones, growth factors, and drugs [2, 32, 64].

In order to analyze the mechanism of TNF action in melanoma, we decided to analyze the effect of TNF on Bomirski $(\mathrm{Ab})$ amelanotic melanoma in the hamster. It is a transplantable, highly stable tumor with a behavior resembling the clinical situation. Ab melanoma is a relatively immunogenic, quickly growing tumor with a mean survival time of tumor-bearing animals of about 25 days. The primary tumor metastasizes mostly to the kidneys and lymph nodes $[10,11]$. Ab melanoma is also sensitive to the cytotoxic effect of natural killer (NK) cells at the metastasis formation stage [9] and the tumor's presence alone can increase the cytotoxic activity of macrophages and NO release [34]. However, tumor growth can also induce immunosuppression in tumor-bearing animals [45]. Therefore, in the $\mathrm{Ab}$ melanoma model one may possibly analyze all the aspects of TNF's effect on tumor growth and metastasis.

\section{MATERIALS AND METHODS}

\section{Materials}

Recombinant rat TNF with a specific activity of $1.1 \times 10^{8} \mathrm{U} / \mathrm{mg}$ of protein was prepared in our laboratory. The complementary DNA of rat TNF gene was cloned into the pET16b vector (Novagen, USA) under a lactose operon and expressed in the E. coli BL21(DE3) strain. The expressed protein was purified to homogeneity by a combination of chromatographic procedures and the use of Polymyxin B (Sigma, USA) as described in our earlier publication [33]. The endotoxin content was measured by the Limulus amebocyte assay and was found to be $<60 \mathrm{ng} / \mathrm{ml}$. Human recombinant TNF was the generous gift of Dr. Schwendemann (BASF Knoll AG, Germany). Hemisynthetic analogue of fumagillin TNP-470 (AGM-1740) was the generous gift of Takeda Chemical Industries Ltd., Japan.

\section{Administration of rat TNF \\ to hamsters bearing Ab melanoma}

Four-month-old random-bred male Syrian (golden) hamsters were used in the study. They were purchased from the animal colony of the Silesian Medical University (Katowice, Poland) and maintained at our animal facility on a standard diet and water ad libitum. The tumor was an amelanotic variant of Bomirski melanoma, which was maintained by serial passage in hamsters using the suspension method of transplantation [11]. A suspension of melanoma cells from the primary tumor was injected subcutaneously into the right flank of the animal. After 5-8 days, a palpable tumor was observed. Rat TNF was then injected intratumorally for a period of 10 days, once a day between 10 and 12 a.m. at a dose of 20 or $40 \mu \mathrm{g}$ in an injection volume of $0.25 \mathrm{ml}$. Control tumor-bearing animals received injections of $0.25 \mathrm{ml}$ of vehicle $(20 \mathrm{mM}$ Tris, $300 \mathrm{mM} \mathrm{NaCl}$, $0.1 \%$ BSA, $\mathrm{pH}$ 8.0). Three dimensions of a tumor were measured daily and its surface and volume were then calculated. The animals were killed by decapitation on days 21-23 after the tumor injection at the onset of irrevocable cachexia. After decapitation, autopsy was done and the tumors were excised and weighed. Only the animals used for the preparation of histological slides and the isolation of blood serum, splenocytes, and peritoneal macrophages were killed after three days of TNF treatment and/or 8-11 days of TNP-470 treatment (8-11 days after tumor implantation).

All animal experiments were performed with permission of the Local Ethics Commission, Medical University of Gdańsk, and in agreement with the guidelines thereof.

\section{Administration of TNP-470 \\ to hamsters bearing Ab melanoma}

$\mathrm{Ab}$ amelanotic melanoma implantation was conducted as described above. From the day of tumor implantation on, TNP-470 was daily injected subcutaneously into the flank opposite the tumor at a dose of $30 \mathrm{mg} / \mathrm{kg}$ of body mass and in a volume of $0.5 \mathrm{ml}$. Control tumor-bearing animals were given injections for 21 days of $0.5 \mathrm{ml}$ of vehicle $(0.1 \%$ ethanol solution with $5 \%$ of Arabic gum). The animals were subsequently killed as described above.

\section{Preparation of microscope slides of tumors}

Microscope slides were prepared from tumors 8-11 days after tumor implantation. Excised tumor sections were fixed in formalin and embedded in paraffin. Paraffin sections were stained with hematoxylin and eosin using the method of May-Grünewald-Giemsa.

\section{Preparation of the cell isolates}

Splenocytes or tumor cells were isolated by pressing spleens or primary tumors through a 0.1-mm-pore strainer and then purified by centrifugation on Ficoll 400 (Pharmacia, Sweden) and Uropolin (Polfa, Poland) gradient. Contaminating erythrocytes were hemolysed with cold distilled water and purified cells were washed with phosphate buffered saline (PBS).

Peritoneal macrophages were harvested from animals injected i.p. with $10 \mathrm{ml}$ of thioglycolate broth (2.98\% solution; Difco, USA) 5 days earlier. Cells were washed out from the peritoneal cavity with PBS, filtered through a $0.05-\mathrm{mm}$-pore strainer and purified by centrifugation on Dextran (MW=70.000) and Uropolin (Polfa, Poland) gradient.

Splenocytes and thioglycolate-elicited peritoneal 
macrophages were isolated from healthy animals, tumor-bearing animals, and tumor-bearing animals injected intratumorally with TNF at a dose of $20 \mu \mathrm{g}$ for three days from the moment the tumor had become palpable and 8-11 days from tumor implantation.

\section{Assay for the cytotoxic activity of TNF} on Ab cells in primary culture

The cytotoxic activity of TNF was measured with the (3-[4,5-dimethylthiazol-2-yl]-2,5-diphenyltetrazolium bromide (MTT) assay [44]. Isolated tumor cells were seeded in a 96-well plate at a density of $5 \times 10^{4}$ cells per well with serial dilutions of rat TNF in $0.1 \mathrm{ml}$ of culture medium consisting of F-10 (Biomed, Poland), 10\% fetal bovine serum (FBS; Gibco, USA), $100 \mathrm{U} / \mathrm{ml}$ penicillin, and $0.1 \mathrm{mg} / \mathrm{ml}$ streptomycin and incubated at $37^{\circ} \mathrm{C}$ in $5 \% \mathrm{CO}_{2}$. After $45 \mathrm{~h}$ of incubation, $20 \mu \mathrm{l}$ of a $5 \mathrm{mg} / \mathrm{ml}$ MTT solution (Sigma, USA) was added to each well and incubation was continued for $3 \mathrm{~h}$ at $37^{\circ} \mathrm{C}$ with $5 \% \mathrm{CO}_{2}$ to allow MTT metabolization. The resultant formazan crystals were dissolved by adding $100 \mu \mathrm{l}$ of isopropyl alcohol with $0.4 \mathrm{~N} \mathrm{HCl}$ per well [44]. The optical density at $630 \mathrm{~nm}$ was measured using a Multiscan MCC/340P microplate reader (Labsystems, Finland). The optical density of wells containing cells cultured without TNF was assumed to be $100 \%$ of cell viability.

\section{Assay for the cytotoxic activity of TNF \\ on tumor cells in primary culture enriched \\ in splenocytes or peritoneal macrophages}

Splenocytes and peritoneal macrophages were isolated from healthy and tumor-bearing animals as above. Splenocytes were either irradiated (3600 Gy, $7 \mathrm{~min}$ ) or not irradiated. Purified tumor cells were seeded into a 96-well plate at a density of $5 \times 10^{4}$ cells/well, macrophages at $1 \times 10^{5}$ cells/well, and splenocytes at $2.5 \times 10^{5}$ cells/well with a serial dilution of rat TNF in $0.1 \mathrm{ml}$ of culture medium with the composition as above at $37^{\circ} \mathrm{C}$ in $5 \% \mathrm{CO}_{2}$. The TNF effect on tumor cells in co-cultures with the effector cells was measured by the MTT assay or by the /methyl- ${ }^{3} \mathrm{H} /$-thymidine incorporation assay. The MTT assay [44] was performed as described above. The optical density of wells containing cells cultured without TNF was assumed to be $100 \%$ of cell viability, separately for each co-culture of cells. For the isotopic method, the co-cultures were pulse-labeled with $/$ methyl- ${ }^{3} \mathrm{H} /-$ -thymidine $(1 \mu \mathrm{Ci} /$ well; Polatom, Poland $)$ for $6 \mathrm{~h}$ before harvest with an automatic cell harvester (Skatron Instruments, USA) $45 \mathrm{~h}$ after the culture initiation. Radioactivity of the samples was measured with an LS60001C liquid scintillation counter (Beckman, USA).

\section{Assay for the NK cytotoxic activity of splenocytes} and the natural cytotoxicity of macrophages in vivo

Splenocytes and peritoneal macrophages were isolated from healthy animals, tumor-bearing animals, and tumor-bearing animals treated with TNF as described above. The NK cytotoxic activity of splenocytes was measured by the ${ }^{51} \mathrm{Cr}$ release assay on K562 target cells. Target cells were labeled for one hour by $0.1 \mathrm{mCi}$ of $\mathrm{Na}_{2}{ }^{51} \mathrm{CrO}_{4}$ (Polatom, Poland) for $2 \times 10^{7}$ cells in $0.1 \mathrm{ml}$ of RPMI (Biomed, Poland) with 20\% FBS and then seeded in a 96-well plate at a density of $2 \times 10^{4}$ cells/well. The splenocytes were added at the effector:target ratios of 5:1, 10:1, and 25:1 for splenocytes from the healthy animals and 25:1 for the other splenocytes. The cells were incubated for $4 \mathrm{~h}$ in $0.2 \mathrm{ml}$ of culture medium consisting of RPMI, $10 \%$ FBS, $\beta$-merkaptoethanol, $100 \mathrm{U} / \mathrm{ml}$ penicillin, and $0.1 \mathrm{mg} / \mathrm{ml}$ streptomycin. The activity of released isotope in culture medium was measured with a gamma counter (Minigamma Spline, Germany). The percentage of specific ${ }^{51} \mathrm{Cr}$ release was calculated as:

$$
\% \text { of specific }=\frac{\begin{array}{c}
\text { experimental release } \\
{ }^{51} \mathrm{Cr} \text { release }
\end{array}=\frac{\text { spontaneous release }}{\text { total release }}}{- \text { spontaneous release }}
$$

Experimental release is the radioactivity released in wells containing activated effector cells and target cells; spontaneous release the radioactivity released from target cells incubated in the medium alone, and total release the radioactivity from target cells lysed with $75 \%$ acetic acid. The spontaneous release was less than $5 \%$ of the total release. Each test group was assayed in triplicate or quadruplicate and all the experiments were repeated at least 3 times.

The cytotoxic activity of macrophages in vitro was measured by the /methyl- ${ }^{3} \mathrm{H} /$-thymidine incorporation assay on K562 target cells. Target cells were seeded in a 96-well plate at a density of $5 \times 10^{4}$ cells/well. Macrophages were added at the effector:target ratios of $0.1: 1,0.5: 1$, and $1: 1$ for macrophages from the healthy animals and 1:1 for the other macrophages. Cells in 0.1 $\mathrm{ml}$ of culture medium consisting of RPMI, $10 \%$ FBS, $5 \times 10^{-5} \mathrm{M} \beta$-merkaptoethanol, $100 \mathrm{U} / \mathrm{ml}$ penicillin, and $0.1 \mathrm{mg} / \mathrm{ml}$ streptomycin were pulse-labeled with /methyl- ${ }^{3} \mathrm{H} /$-thymidine $(1 \mu \mathrm{Ci} /$ well $)$ for $4 \mathrm{~h}$ before harvest with an automatic cell $20 \mathrm{~h}$ after culture initiation. The radioactivity of the samples was measured with an LS60001C liquid scintillation counter.

\section{Quantitative determination of cytokine concentrations in blood serum samples}

Blood samples were isolated under general anesthesia from the hearts of tumor-bearing animals 8-11 days after tumor implantation and three days of TNF or vehicle treatment from the moment the tumor had become palpable or from healthy animals of the same age. The animals were then killed by decapitation. Serum was obtained by blood coagulation and centrifugation.

The TNF concentration was measured by a standard cytotoxic assay coupled with the neutral red uptake assay [70]. One day before the assay, TNF-sensitive mouse A9 
fibroblastic cells were seeded in a 96-well plate at a density of $3 \times 10^{4}$ cells/well in $0.1 \mathrm{ml}$ of culture medium consisting of DMEM (Biomed, Poland), 10\% FBS, $4 \mathrm{mM}$ L-glutamine, $100 \mathrm{U} / \mathrm{ml}$ penicillin, and $0.1 \mathrm{mg} / \mathrm{ml}$ streptomycin. The cells were incubated for $9 \mathrm{~h}$ with blood serum samples at a dilution of 1:10 in the culture medium with cycloheximide $(0.25 \mathrm{mg} / \mathrm{ml})$. Human recombinant TNF dilutions were used for plotting the standard curve.

Interleukin (IL)-6 activity was measured by a proliferative assay coupled with the $/$ methyl $-{ }^{3} \mathrm{H} /$-thymidine incorporation assay. Mouse B9 myeloma cells were seeded in a 96-well plate at a density of $1 \times 10^{4}$ cells per well in $0.1 \mathrm{ml}$ of culture medium consisting of RPMI, $10 \%$ FBS, $5 \times 10^{-5} \mathrm{M} \beta$-merkaptoethanol, $100 \mathrm{U} / \mathrm{ml}$ penicillin, and $0.1 \mathrm{mg} / \mathrm{ml}$ streptomycin. The cells were incubated for $68 \mathrm{~h}$ with a blood serum sample at a dilution of $1: 10$ or a serially diluted supernatant from the murine splenocyte culture (obtained from Dr. M. Cichorek, Laboratory of Embryogenesis, Medical University of Gdańsk). This supernatant was prepared by $48 \mathrm{~h}$ of culture in RPMI with 5\% FBS and $10 \mu \mathrm{g} / \mathrm{ml}$ of Concanavalin A and then titrated against recombinant IL-6. After incubation the cells were pulse-labeled with /methyl- ${ }^{3} \mathrm{H} /$-thymidine $(1 \mu \mathrm{Ci} /$ well $)$ for $4 \mathrm{~h}$ before harvest with an automatic cell harvester. The radioactivity of the samples was measured with an LS60001C liquid scintillation counter.

\section{Statistical analysis}

Statistical analysis for the tumor growth rate was performed with a combination of Morgan test and Student's $t$-test distribution analysis. Statistical analysis for the rate of appearance of advanced hemorrhagic necrosis was performed with the Fisher test using the Statistica program (StatSoft Inc., USA).

\section{RESULTS}

\section{The effect of rat TNF on the growth of hamster Ab melanoma}

In order to analyze the effect of rat TNF on $\mathrm{Ab}$ melanoma growth in vivo, rat TNF was applied intratumorally for a period of 10 days from the moment the tumor had become palpable. The rate of tumor growth in vehicle- and TNF-treated tumor-bearing hamsters is shown in Fig. 1A. In vehicle-treated tumor-bearers, $\mathrm{Ab}$ melanoma developed rapidly. There was also no difference between the results from untreated tumor-bearers, vehicle-treated, and animals treated with inactivated TNF (incubated for $30 \mathrm{~min}$ at $100^{\circ} \mathrm{C}$, the data not shown). In TNF-treated animals, tumor growth was partially inhibited. The differences in tumor volume between control and TNF-treated animals were statistically significant from the 4th day of TNF treatment. The differences lasted till the day of the death of the animals and were reflected in the differences in tumor mass as
A
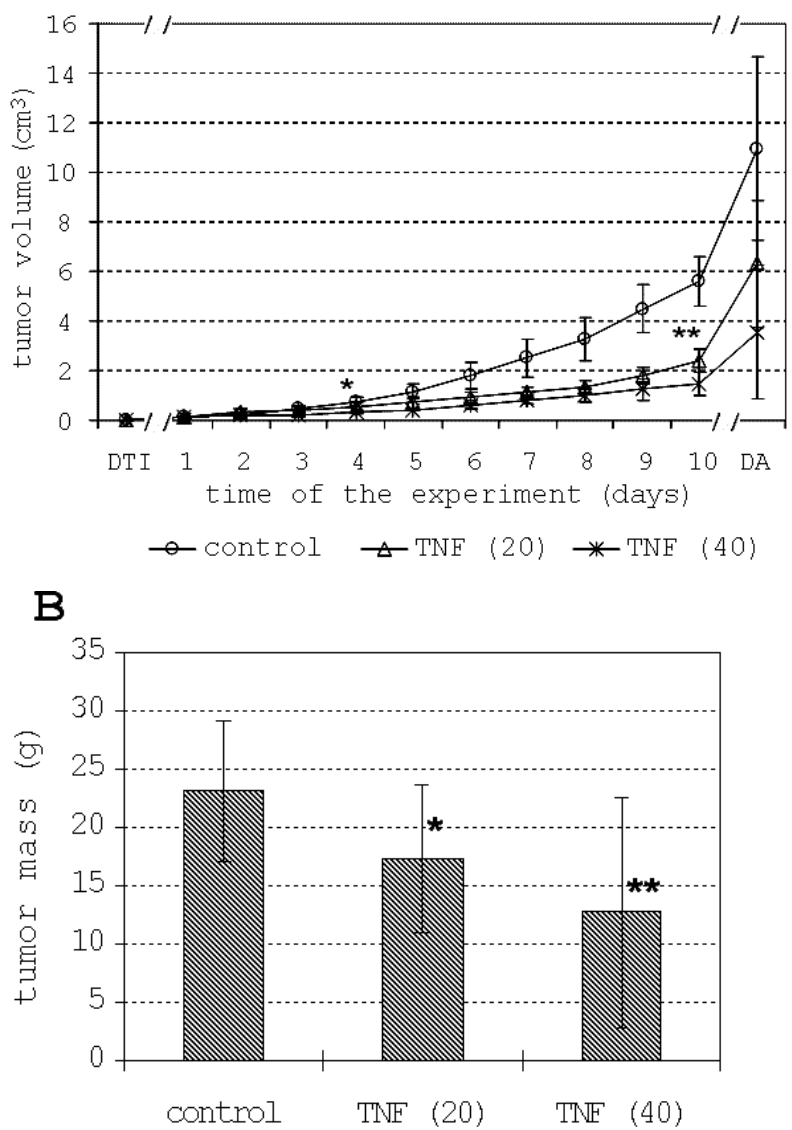

Fig. 1. Dose-dependent inhibitory effect of rat TNF on $\mathrm{Ab}$ melanoma growth in vivo. TNF at a dose of 20 or $40 \mu \mathrm{g}$ per injection was applied intratumorally. Control animals were injected with vehicle (see Materials and Methods). Graph A represents average measurements of the tumor volume during experiments. Graph B represents average tumor mass on the day of autopsy. Mean deviations are indicated. Results were obtained from 18 control animals and from 13 or 5 animals injected with TNF in the dose of 20 (TNF (20)) or $40 \mu \mathrm{g}$ (TNF (40)), respectively (from 5 independent experiments). The differences between the growth rates of the tumors of control animals and animals injected with TNF were statistically significant from day 4 of treatment (*) and between two doses of TNF at day $10(* *)$. The differences were also significant for tumor mass between control and TNF-treated animals (*) on the day of autopsy $(\mathrm{p}<0.05)$. DTI - day of tumor implantation, DA - day of autopsy.

shown in Fig. 1B. The inhibitory effect of TNF on tumor growth was dose dependent since the effect of $40 \mu \mathrm{g}$ TNF per day was significantly stronger than the effect of the $20-\mu \mathrm{g}$ dose on the 10th day of tumor treatment. There was also one case of complete regression of tumor induced by treatment with a $40-\mu \mathrm{g}$ dose of TNF. Therefore, TNF intratumoral injections inhibited $\mathrm{Ab}$ melanoma growth in a dose-dependent manner.

\section{The effect of TNF treatment on systemic metastasis of Ab melanoma and survival of tumor-bearing animals}

Ab melanoma metastasizes mostly to the kidneys and lymph nodes. Intratumoral application of TNF 
Table 1. Effect of TNF application on systemic metastasis of Ab melanoma

\begin{tabular}{lccccc}
\hline & \multicolumn{4}{c}{ Percentage of animals with tumor metastases present in the indicated organs } \\
\cline { 2 - 6 } & kidneys & liver & mediastinum & $\begin{array}{c}\text { armpit } \\
\text { lymphatic nodes }\end{array}$ & $\begin{array}{c}\text { lungs and } \\
\text { peritoneal cavity }\end{array}$ \\
\hline Controls $(\mathrm{n}=15)$ & $93 \%$ & $20 \%$ & $87 \%$ & $93 \%$ & $27 \%$ \\
\hline TNF 20 $(\mathrm{n}=11)$ & $46 \%$ & $9 \%$ & $91 \%$ & $91 \%$ & $36 \%$ \\
\hline TNF 40 $(\mathrm{n}=5)$ & $20 \%$ & $40 \%$ & $100 \%$ & $60 \%$ & $100 \%$ \\
\hline
\end{tabular}

TNF at a dose of $20 \mu \mathrm{g}$ (TNF 20) or $40 \mu \mathrm{g}$ (TNF 40) per injection was applied intratumorally. Control animals were injected with vehicle.

changed the pattern of systemic metastasis. The most evident effect of TNF treatment was a lower incidence of kidney metastases (Table 1). This effect was dose dependent and statistically significant, as shown by the non-parametric Fisher test at a p value of less than 0.02. TNF also significantly augmented the frequency of metastasis to the peritoneal cavity and the lungs in the animals treated with TNF at a dose of $40 \mu \mathrm{g} /$ day in comparison with the control animals (Table 1). Notwithstanding the effect on $\mathrm{Ab}$ melanoma growth and metastasis, the therapy with TNF did not significantly affect animal survival. TNF treatment also caused no weight reduction compared with the control tumor-bearing animals (data not shown).

\section{The effect of TNF treatment on tumor hemorrhagic necrosis}

The effect of TNF on Ab melanoma vasculature was analyzed mostly by its effect on hemorrhagic necrosis of tumors. Advanced hemorrhagic necrosis, manifesting as a tumor perforation and a clot on its surface, was absent in some of the control animals, but all of the TNF-treated animals showed its signs. As seen in Fig. 2, intratumorally injected TNF also had a statistically significant acceleratory effect on the appearance of advanced tumor hemorrhagic necrosis during the period of TNF treatment compared with the control animals.

\section{Histological examination of tumors treated with TNF and the angiogenesis inhibitor TNP-470}

To analyze the effect of TNF on tumor blood vessels in the $\mathrm{Ab}$ melanoma model, we decided to use a known angiogenesis inhibitor, TNP-470, for comparison and as a possible synergistic agent. TNP-470 is a hemisynthetic fumagillin analogue which not only inhibits angiogenesis [7, 29], also in Ab melanoma [46, 47], but has a cytostatic and cytotoxic effect on endothelial cells $[27,73]$.

Histological examination of tumors was done at the early stage of tumor growth. Even a short, 3-day period of TNF injections at a dose of $20 \mu \mathrm{g} / \mathrm{day}$ was sufficient to cause changes in tumor tissues. These changes were expressed as areas of fibrosis and accumulations of tumor cells with nuclear pyknosis and karyorrhexis (Fig. 3B). There were no such changes in the control tumors

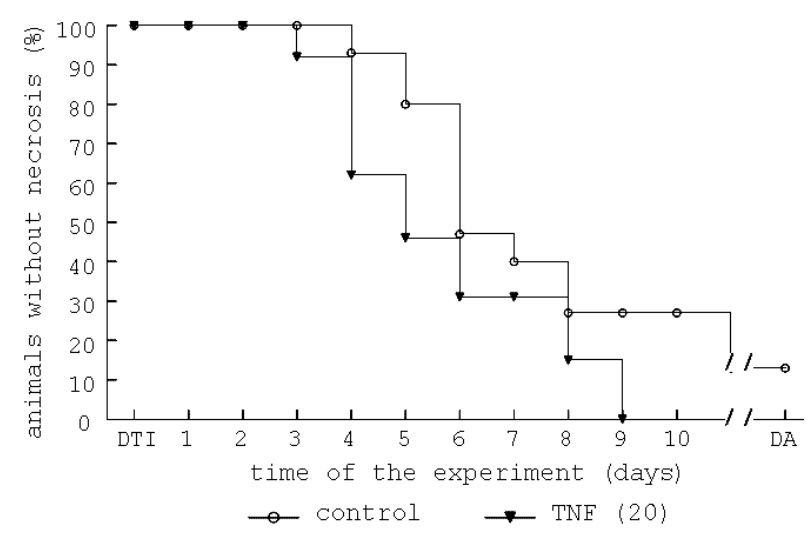

Fig. 2. Acceleratory effect of rat TNF on the rate of appearance of advanced tumor hemorrhagic necrosis. TNF at a dose of $20 \mu \mathrm{g}$ per injection was applied intratumorally to hamsters bearing $\mathrm{Ab}$ melanoma. Control animals were injected with vehicle (see Materials and Methods). Advanced hemorrhagic necrosis manifested as perforation of tumor and a clot on its surface. Its appearance was measured as the percentage of animals manifesting it for all control and TNF-treated animals. The differences were statistically significant between control animals (11 animals with advanced necrosis from 17 animals) and animals injected with TNF (13 from 13) after 10 days of intratumoral injections $(\mathrm{p}=0.02)$. DTI - day of tumor implantation, DA - day of autopsy.

(Fig. 3A), which were injected intratumorally with a vehicle in the same volume as the TNF preparation. This seems to indicate that the changes were not a result of mechanical damage. TNF treatment did not cause visible injury to the tumor vessels. Such injury and erythrocyte extravasation could be seen on histological sections of tumors treated with the hemisynthetic inhibitor of angiogenesis TNP-470 (Fig. 3C). Furthermore, this effect of TNP-470 on tumor vasculature was augmented by TNF in the combined treatment (Fig. 3D).

\section{The mechanism of the TNF effect on tumor cells in vitro}

In order to analyze the possible mechanism of TNF action on tumor cells in Ab melanoma, first the effect of TNF on the viability of tumor cells in primary culture was measured. TNF displayed a dose-dependent cytotoxic effect on $\mathrm{Ab}$ tumor cells in primary culture as shown in Fig. 4. However, apart from amelanoma cells 

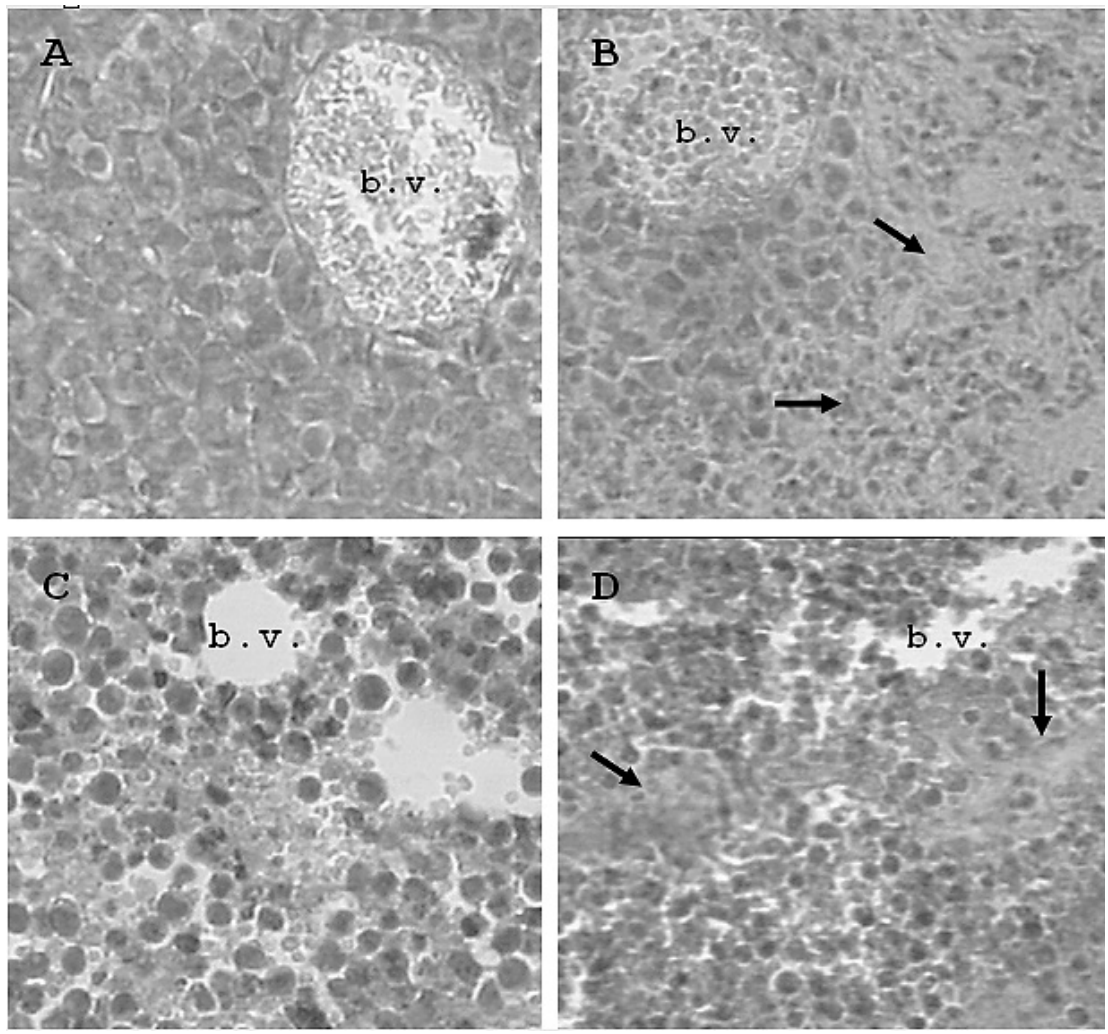

Fig. 3. Effect of rat TNF and TNP-470 on tumor tissues. Photographs show representative histological sections of the tumors from 5 independent experiments $(\mathrm{n}=2$ for each group in each experiment) from: $\mathbf{A}-$ control animals treated intratumorally and subcutaneously with vehicle, B - animals injected intratumorally with TNF at a dose of $20 \mu \mathrm{g}, \mathbf{C}$ - animals injected subcutaneously with TNP-470 at a dose of $30 \mathrm{mg} / \mathrm{kg}$ of body weight, and $\mathbf{D}$ - animals injected with TNF and TNP-470 (see Materials and Methods). Microscope slides were prepared from tumors 10 days after tumor implantation. Excised sections of tumors were fixed in formalin, embedded in paraffin, and stained with a hematoxylin and eosin. The arrows indicate areas of fibrosis and accumulations of tumor cells with nuclear pyknosis and karyorrhexis. b.v. blood vessel.

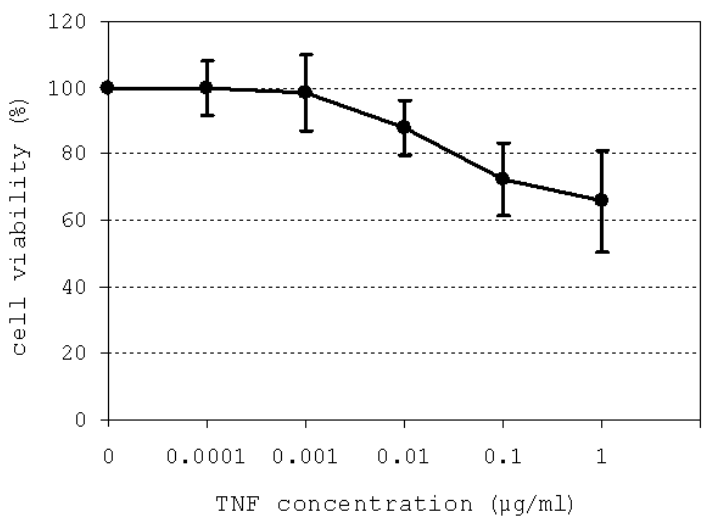

Fig. 4. Dose-dependent cytotoxic effect of rat TNF on Ab tumor cells in primary culture. The curve is an average of 8 independent MTT tests. The mean deviations are marked.

in those cultures, there were also mononuclear cells infiltrating the tumor, such as lymphocytes and macrophages. Accordingly, the next two series of experiments were performed to discover whether the TNF effect on $\mathrm{Ab}$ cells in primary culture was direct and independent of the presence of immunomodulatory cells.

The analysis aimed first at discovering whether there were any changes in the cytotoxic effect of TNF on $\mathrm{Ab}$ tumor cells in cultures enriched with lymphocytes or macrophages isolated from the tumor-bearing animals or from the healthy, non-tumor-bearing animals. A possible effect of TNF on lymphocytes or macrophages

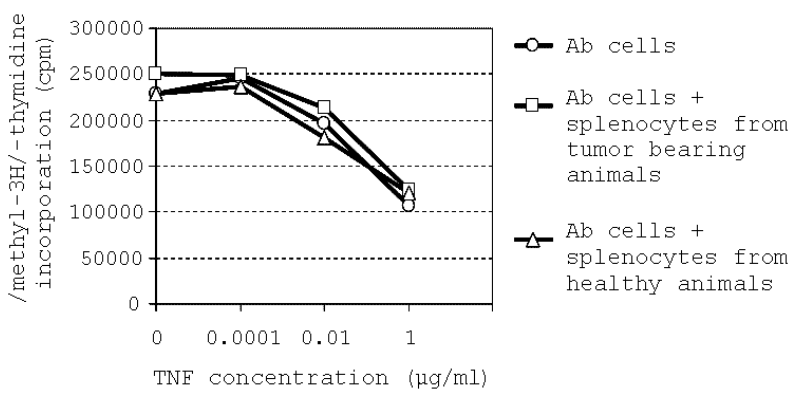

Fig. 5. Effect of enrichment of primary culture with splenocytes on the cytotoxic effect of rat TNF on Ab tumor cells (ratio of Ab cells to splenocytes: $1: 5)$ as measured by the $/$ methyl $-{ }^{3} \mathrm{H} /$-thymidine incorporation assay. Splenocytes were isolated from tumor-bearing animals or from healthy, non tumor-bearing animals. The /methyl- ${ }^{3} \mathrm{H} /$-thymidine incorporation level by splenocytes alone was stable at a level of 2000-3500 cpm and was not affected by TNF concentration. As there was no difference between the results concerning irradiated or non-irradiated splenocytes, only the results concerning the former are shown. The graph shows the average results of 8 independent tests.

could influence the cytotoxic effect on Ab melanoma cells. Enrichment of the Ab tumor primary culture with isolated splenocytes containing NK lymphocytes did not change the dose-dependent cytotoxic effect of TNF on $\mathrm{Ab}$ melanoma cells as measured by the $/$ methyl $^{3}{ }^{3} \mathrm{H} /-$ -thymidine incorporation assay (Fig. 5). There was also no change in the proliferation of the tumor cells as measured by the MTT proliferation assay (data not shown). 


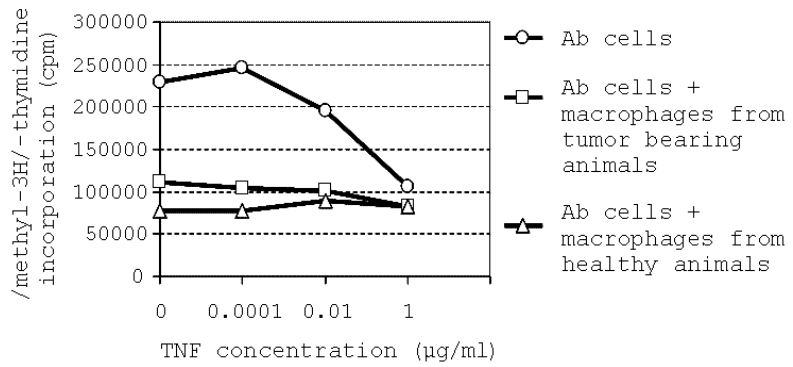

Fig. 6. Effect of enrichment of primary culture with peritoneal macrophages on the cytotoxic effect of rat TNF on Ab tumor cells (ratio of Ab cells to macrophages: 1:2) as measured by the /methyl$-{ }^{3} \mathrm{H} /$-thymidine incorporation assay. Peritoneal macrophages were isolated from tumor-bearing animals or from healthy, non-tumor-bearing animals. The /methyl- ${ }^{3} \mathrm{H} /$-thymidine incorporation level by macrophages alone was stable and negligible at a level of 800-1000 $\mathrm{cpm}$. The graph shows the average results of 8 independent tests.

Since TNF did not affect the viability or the proliferation rate of splenocytes alone, the inhibitory effect of TNF on the primary cell culture is probably independent of lymphocyte-related mechanisms.

Similar experiments were performed on $\mathrm{Ab}$ melanoma cell cultures under conditions of enrichment with peritoneal macrophages. Measurements of $\mathrm{Ab}$ cells proliferation by the /methyl- ${ }^{3} \mathrm{H} /$-thymidine incorporation assay indicated that macrophages alone inhibited the proliferation of the tumor cells. The addition of TNF into the cell culture enriched with peritoneal macrophages had no significant effect on the proliferation of $\mathrm{Ab}$ melanoma cells (Fig. 6). As there was no decrease in the viability of tumor cells in the presence of macrophages alone as measured by the MTT assay (data not shown), this suggests that macrophages alone have a cytostatic effect on $\mathrm{Ab}$ melanoma cells, probably through secreted TNF, and thus diminish the cytotoxic effects of TNF added to the cell culture. Since recombinant rat TNF did not affect the viability or the proliferation rate of macrophages alone, the inhibitory effect of rat TNF on the primary cell culture is probably independent of macrophage-related mechanisms.

Further experiments involved DNA analysis of tumor cells treated with TNF. DNA was isolated from a one-week-old $\mathrm{Ab}$ cell culture after a 10-hour incubation with or without TNF. Such a culture is free of macrophages and lymphocytes, so the effect of TNF on the tumor cells should be direct. There was an increase in the amount of low-molecular-weight DNA in isolates from the cells incubated with TNF, as shown in Fig. 7. Low-molecular-weight DNA seen as an apoptotic ladder is an indication of apoptotic death of the cells. An increase in the level of apoptotic death was also detected by flow cytometry (data not shown). The TNF cytotoxic effect on $\mathrm{Ab}$ melanoma cells in vitro is, therefore, most probably exerted directly on tumor cells through some enhancement of apoptotic cell death.

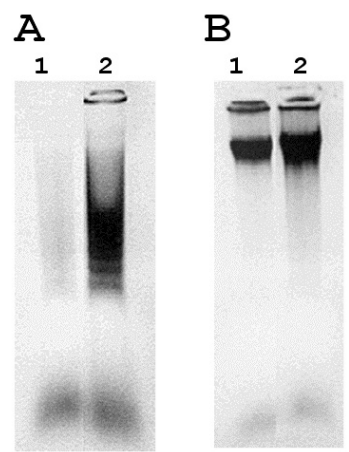

Fig. 7. Increased apoptotic death of Ab melanoma tumor cells as a result of TNF cytotoxic activity. The photographs of $1 \%$ agarose gel show DNA isolated from one-week-old Ab cell cultures after $10 \mathrm{~h}$ incubation with or without TNF. Photograph A shows supernatants with the low-molecular-weight DNA, photograph B shows pellets with the high-molecular-weight DNA. Lanes: 1 - cells incubated without TNF (control), 2 - cells incubated with TNF (1 $\mu \mathrm{g} / \mathrm{ml}$ of culture medium). An increased amount of low-molecularweight DNA seen as an apoptotic ladder is visible on the gel lane of the supernatant of low-molecular-weight DNA isolated from the cells incubated with TNF.

\section{The influence of intratumoral injections of TNF} on the activity of NK lymphocytes and macrophages in vivo

In order to determine whether the anti-tumor activity of TNF in vivo is in part a result of its augmenting effect on the natural cytotoxic activity of NK lymphocytes and/or macrophages, these cells were isolated from healthy animals, tumor-bearing animals, and tumor-bearing animals injected intratumorally with TNF at a dose of $20 \mu \mathrm{g}$ for 3 days from the moment the tumor had become palpable. Subsequently, the cytotoxic activity of NK lymphocytes was measured by the ${ }^{51} \mathrm{Cr}$ release assay and the cytotoxic activity of the macrophages was measured by the /methyl- ${ }^{3} \mathrm{H} /$-thymidine incorporation assay with the K562 target cells. Figure 8 shows that the cytotoxic effect of NK lymphocytes was dependent on their concentration and was not affected by intratumoral application of TNF. Figure 9 shows, in turn, that there was also no stimulation of natural cytotoxic activity of macrophages. These results indicate that intratumoral injections of TNF did not significantly stimulate the activity of peripheral immunomodulatory cells in vivo.

\section{The effect of TNF treatment on the cytokine concentration in the blood}

The concentration of cytokines was measured in the blood serum of healthy animals, tumor-bearing animals, and tumor-bearing animals injected intratumorally with $\mathrm{TNF}$ at a dose of $20 \mu \mathrm{g}$ for three days from the moment the tumor had become palpable. The results shown in Fig. 10A indicate that intratumoral injections of TNF did not significantly increase the amount of TNF in the 


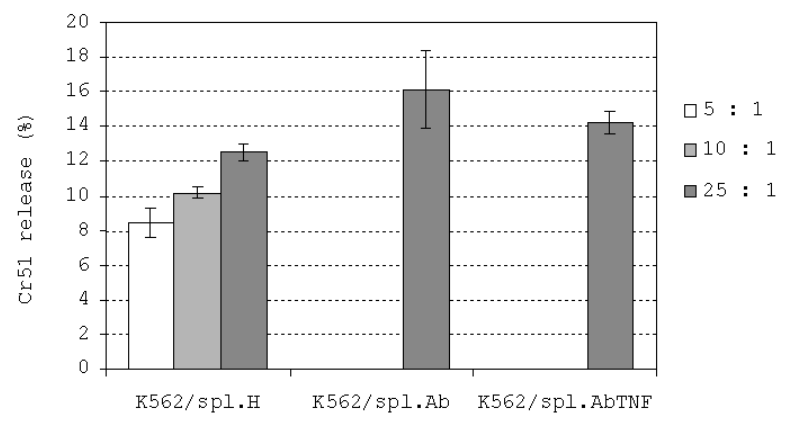

Fig. 8. Cytotoxic activity of NK lymphocytes in vitro as measured by the ${ }^{51} \mathrm{Cr}$ release assay on K562 target cells. Splenocytes containing NK lymphocytes were isolated from healthy animals (spl.H), tumor-bearing animals (spl.Ab), and tumor-bearing animals injected intratumorally with TNF at a dose of $20 \mu \mathrm{g}$ for 3 days from the moment the tumor had become palpable (spl.AbTNF). The ratios of effector to target cells were 5:1, 10:1, and 25:1 for splenocytes from healthy animals and 25:1 for other splenocytes. The graph shows the results of 3 independent experiments $(n=2$ for each group in each experiment). The mean deviations are marked.

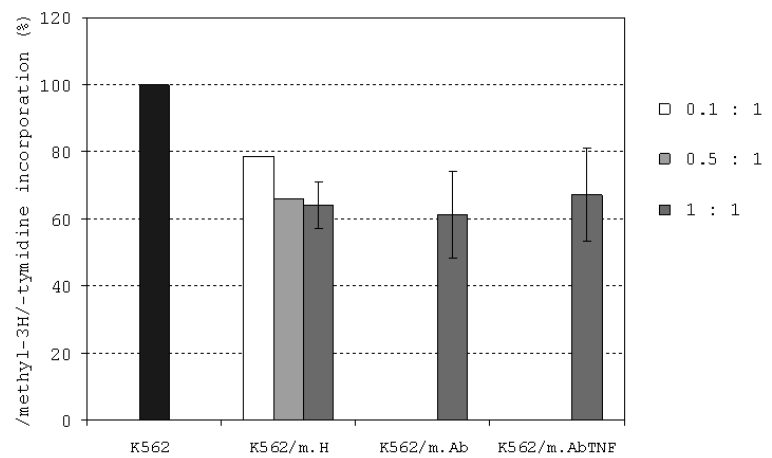

Fig. 9. Cytotoxic activity of macrophages in vitro as measured by the /methyl- ${ }^{3} \mathrm{H}$-thymidine incorporation assay on K562 target cells. Peritoneal macrophages were isolated from healthy animals (m.H), tumor-bearing animals (m.Ab), and tumor-bearing animals injected intratumorally with TNF at a dose of $20 \mu \mathrm{g}$ for three days from the moment the tumor had become palpable (m.AbTNF). The ratios of effector to target cells were $0.1: 1,0.5: 1$, and $1: 1$ for macrophages from healthy animals and 1:1 for other macrophages. The graph shows the results of 4 independent experiments ( $\mathrm{n}=2$ for each group in each experiment). The mean deviations for the $1: 1$ ratio are marked.

blood of tumor-bearing animals. However, there were significant changes in the concentrations of cytokines with IL-6 activity as a result of TNF treatment (Fig. 10B). The latter result suggests that the intratumoral application of TNF affects in some manner the immune system of $\mathrm{Ab}$ melanoma-bearing animals, possibly by stimulating the acute-phase response.

\section{DISCUSSION}

Only a few kinds of melanoma tumors are commonly used to analyze the effects of TNF on the growth and
A

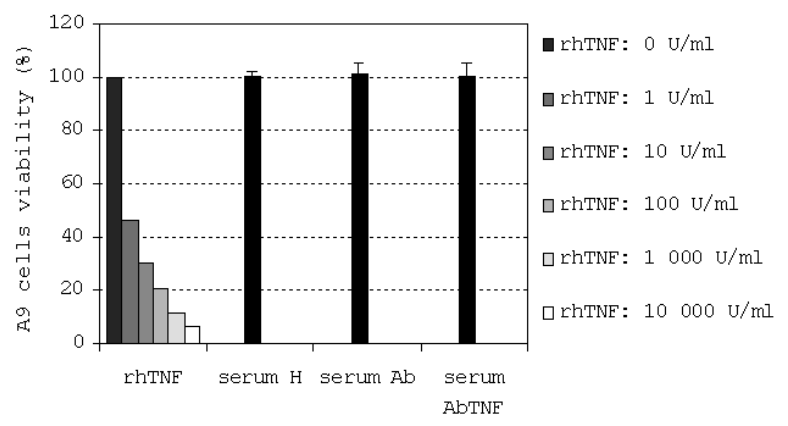

B

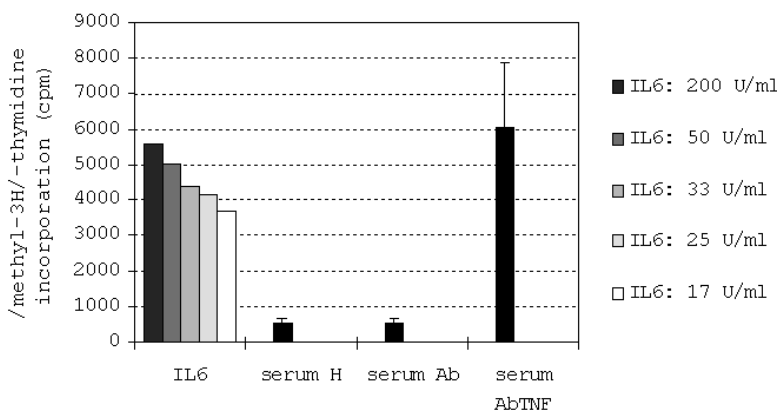

Fig. 10. Concentration of cytokines in the blood serum of healthy animals (serum $\mathrm{H}$ ), tumor-bearing animals (serum $\mathrm{Ab}$ ), and tumor-bearing animals injected intratumorally with TNF at a dose of $20 \mu \mathrm{g}$ for three days from the moment the tumor had become palpable (serum AbTNF). Graph A shows the concentration of TNF measured as the cytotoxic activity on the standard TNF-sensitive A9 cell line. The standard curve was established using human recombinant TNF (BASF Knoll AG, Germany). Graph B shows the concentration of cytokines with the activity of IL-6 measured as a proproliferative effect on the IL-6-dependent B9 cell line. The standard curve was established using supernatant from a murine splenocyte culture (48 h, RPMI with 5\% FBS) with an activity of $1000 \mathrm{U} / \mathrm{ml}$. The results are from 5 independent experiments ( $\mathrm{n}=2$ for each group in each experiment).

metastasis of melanoma. The most known is mouse B16 melanoma, a melanin-producing tumor which is highly sensitive to TNF and its hypopigmenting activity [14]. This paper analyzes the mechanism of TNF action in Bomirski (Ab) amelanotic melanoma and its usefulness in studies of TNF as an anti-tumor agent. Ab melanoma is a stable and widely studied tumor in our laboratory. Some of its useful characteristics are: a high rate of tumor growth, a high frequency and stability of metastasis spread, and also some level of immunogenicity [8-11, $33,45,47]$.

By using recombinant rat TNF in a hamster model we took advantage of the limited species specificity of TNF $[38,58]$. This was confirmed in our laboratory by demonstrating a cytotoxic effect of rat TNF on the human U937 and HeLa cell lines, mouse A9 cell line, and later on hamster $\mathrm{Ab}$ melanoma cells ([33], data not shown). TNF was applied intratumorally to subcutaneously implanted $\mathrm{Ab}$ melanoma in 3-10 doses from the 
moment the tumor had become palpable. We chose this mode of application because of its lower toxicity at high doses of TNF. Intratumoral application of TNF is used in clinical applications, for example in the local treatment of liver metastases $[28,31]$ and in the treatment of advanced prostate cancer [36], with a significant anti-tumor effect and mild and transient toxic effects. Additionally, in some experimental models, TNF applied intratumorally or intravenously affected tumor growth similarly, even with a stronger dependence of its anti-tumor effect of intravenous application on the immune system [21]. The chosen mode of TNF injection also let us better evaluate the mechanism of TNF effect on the growth and metastasis of $\mathrm{Ab}$ melanoma at the early stage of its growth, before the development of strong tumor vasculature (primary tumor up to 2-3 mm in diameter).

Having obtained evidence that TNF has a cytotoxic effect not only on the TNF-sensitive A9 cell line, but also on $\mathrm{Ab}$ melanoma cells in vitro, we found that the intratumoral application of an immune modulator such as TNF to hamsters bearing Ab melanoma resulted in a significant inhibition of tumor growth. However, there was only one case of complete regression caused by treatment with very high doses of TNF, and the survival time of the Ab melanoma-bearing hamsters did not differ from that of the control animals. TNF mostly induced only a partial regression of tumors. The therapeutic effect of TNF was, therefore, weaker than in similar mouse B16 melanoma, where a partial regression of tumor was achieved by a single TNF injection. The anti-tumor effect of TNF was also much weaker than in the case of mouse MethA sarcoma, where a single intratumoral injection of TNF caused a complete regression of tumor [21] and in the case of mouse sarcoma 180, where a few consecutive injections also led to complete cure $[32,59]$. In the former case, tumor cells were mostly insensitive to TNF and there was a strong effect of TNF on tumor vasculature, and in the latter case TNF was toxic to aneuploid tumor cells without a visible effect on tumor vessels. What was characteristic for both tumors was their visible infiltration with immunomodulatory cells. In yet another case of mouse sarcoma BP, where there was no such infiltration and TNF exerted an influence mostly on tumor vasculature, there was no distinct size reduction of the tumor $[30,59]$. In experiments on Ab melanoma, with inhibition of tumor growth by TNF, there were also distinctive changes in the pattern of the tumor metastasis. Such changes were associated by other authors with changes induced by TNF in mouse B16 melanoma in the expression of vascular cell adhesion molecule 1 on endothelial cells $[25,52]$. The fact that in the Ab melanoma model TNF treatment significantly decreased the incidence of kidney metastases in a dose-dependent way but increased the frequency of metastasis to the peritoneal cavity and the lungs shows that this model can be useful in the analysis of the mechanism of action by which TNF modulates tumor metastasis.
Since some differences were manifested in the mechanism of anti-tumor activity of TNF against different melanomas, some analysis of the mode of TNF action against Bomirski melanoma was performed. After a 3-day treatment of the tumor with TNF there were visible changes in tumor tissues similar to those in the model of MethA sarcoma, with areas of fibrosis and accumulations of tumor cells with nuclear pyknosis and karyorrhexis, but there was no hyperemia of the vessels [31]. Unlike in the model of MethA sarcoma, TNF had a direct toxic effect on the tumor cells. It is documented that TNF has a direct toxic effect on several neoplastic cell lines [51, 63]. This effect can be cytostatic [65] or cytotoxic through necrosis or apoptosis $[17,37]$. For the Ab melanoma tumor cells, the effect of TNF was cytotoxic, caused by an increase in apoptotic death, as documented by DNA analysis and flow cytometry. However, the decrease in viability of the tumor cells during cytotoxic tests was not higher than $50 \%$ even with the high doses of TNF. This may suggest that a cytostatic effect of TNF is not to be excluded. Such a complex activity of TNF can be seen, for example, in the case of MCF-7 human breast tumor, where TNF acts first as a cytostatic agent on cultured tumor cells and then, after a long period of cytostasis, as a strong cytotoxic agent [55]. However, for $\mathrm{Ab}$ tumor cells such a cytotoxic effect could be seen much earlier, after only $10 \mathrm{~h}$ of incubation with TNF. This could, therefore, suggest heterogeneity of the Ab tumor cell population in view of its sensitivity to TNF, similar to cases of human renal cell carcinoma [23] or human colon cancer [43]. This can be supported by our experiments with the Ab melanoma cell lines derived from primary cell cultures that showed a low sensitivity to the cytotoxic effect of TNF (data not shown).

Besides the direct effect on tumor cells, TNF also influenced the immune system of $\mathrm{Ab}$ melanoma hosts. Its response to TNF was clearly indicated by an increased concentration of cytokines with IL-6 activity in blood serum, as in the cases of mouse B16 melanoma [13]. As indicated in some earlier publications, at this early stage of tumor growth, unlike later stages [8], there was no stimulating effect of tumor presence alone on the cytokine level. In this study we found that after 19-20 days of tumor growth there was an increase in IL-6 activity (50\% of animals) and in the level of TNF $(90 \%)$ in the sera of untreated tumor-bearing hamsters, and this correlated with the progression of cachexia. A low concentration of TNF in blood serum at the early stage of tumor development after TNF treatment, therefore, indicated a low toxicity of such an application of TNF. With no distinct toxic effect of TNF, there was also no detectable increase in the natural cytotoxic activity of the immunomodulatory cells participating in tumor control, such as NK cells. This contradicts the fact that TNF stimulates in vitro the cytotoxicity of NK cells towards many tumor cell lines [24, 54] and augments in vivo the activity of peritoneal NK cells [69]. However, TNF can also indirectly suppress the activity 
of NK cells by, among others, stimulation of macrophages to produce prostaglandins $[5,56]$ and by stimulating the expression of MHC I on tumor cells, which results in a decrease in sensitivity to the anti-tumor activity of NK lymphocytes [67]. In the case of mouse sarcoma 180 there was a similar lack of activation of NK lymphocytes by intratumorally applied TNF [32], and in the case of mouse fibrosarcoma CFS1, TNF treatment even caused a decrease in the activity of spleen NK lymphocytes [19, 39].

Along with NK cells, other immunomodulatory cells, such as macrophages, also participate in tumor control. Macrophages exert their cytotoxic activity on tumor cells mostly by TNF secretion $[15,26]$ and $\mathrm{NO}_{2}^{-}$production [26]. In $\mathrm{Ab}$ melanoma there was no detectable increase in the natural cytotoxic activity of macrophages in vivo by intratumorally injected TNF at this early stage of tumor growth. But in vitro, in the primary tumor cell culture enriched with peritoneal macrophages, there was some, probably cytostatic, effect of macrophages alone on tumor cells that was not modulated by adding TNF into the medium. This in effect corroborates the data from the literature which showed that macrophages exerted a cytostatic effect on tumor cells by TNF-induced arrest in G1 phase of the cell cycle, which can make them insensitive to TNF treatment [42]. The absence of some increase in the activity of peritoneal macrophages and spleen NK lymphocytes in the $\mathrm{Ab}$ melanoma model does not exclude the possibility of some local direct or indirect effect of TNF injection on the activity of immunomodulatory cells in tumor tissues. For example, TNF can increase the expressions of adhesion molecules such as intercellular adhesion molecule 1 (ICAM-1) on tumor cells, thus increasing their vulnerability to lysis by macrophages [71]. TNF can also upregulate ICAM-1 shedding from melanoma cells and thus inhibit, by soluble ICAM-1, adherence of NK lymphocytes to tumor cells [6].

In the case of $\mathrm{Ab}$ melanoma it is also possible that TNF treatment affected $\mathrm{T}$ lymphocytes since there was a partial regression of tumor and even one complete regression as an outcome of TNF application. As indicated in the literature, tumor regression is entirely dependent on $\mathrm{T}$ lymphocytes $[4,22,50]$. A suggested mechanism of this process is that TNF activates Th lymphocytes which in turn activate cytotoxic $\mathrm{T}$ lymphocytes (CTL) to destroy tumor cells [3]. Furthermore, some recent experiments on knockout mice have indicated TNF together with perforin and interferon $\gamma$ as a critical triad of effector molecules in anti-tumor activity of CTL [57].

TNF has been also demonstrated to exert some effect on tumor vessels. TNF is known to increase the permeability of tumor vessels; this effect is stronger when TNF is applied intratumorally and not intravenously [16]. TNF exerts its effect on tumor vessels by inducing apoptosis of endothelial cells in angiogenic tumor blood vessels [60], by stimulating neutrophils to damage the endothelium by proteolytic enzymes and toxic oxygen intermediates $[1,66]$, and also by inducting procoagulant activity of the endothelium, which results in tumor ischemia $[48,49]$. The effect of TNF on tumor blood vessels in $\mathrm{Ab}$ melanoma was not visible at the early stage of TNF application when only TNF was injected, but could be seen in combined therapy with TNP-470. TNP-470 is a hemisynthetic fumagillin analogue which not only inhibits angiogenesis [7, 29], also in Ab melanoma [46, 47], but has a cytostatic and cytotoxic effect on endothelial cells as well $[27,73]$. TNF given in combination with TNP-470 caused an increase in extravasation of erythrocytes compared with the effect of fumagillin analogue used alone, and this suggests some effect of TNF on tumor blood vessels. This idea is also supported by the observation in this study that TNF treatment leads to a statistically significant acceleration of advanced hemorrhagic necrosis of $\mathrm{Ab}$ melanoma primary tumor.

At an early stage of tumor growth and with significant differences in tumor size development between TNF-treated and control animals, TNF application by intratumoral injections did not visibly affect the activity of immunomodulatory cells and the permeability of the tumor blood vessels. Therefore, developmental differences were mainly the result of the direct anti-tumor activity of TNF, as indicated in vivo by an increase in the amount of tumor cells with nuclear pyknosis and karryorrhexis and its cytotoxic activity in vitro on the primary culture of tumor cells. However, the effects of TNF application visible at the later stage of tumor growth, as for example accelerated hemorrhagic necrosis, may suggest its influence on tumor vasculature and also, possibly, its immunomodulatory effect. Therefore, hamster $\mathrm{Ab}$ melanoma could be used as a model to analyze different aspects of the anti-tumor action of such a multifunctional cytokine as TNF alone and in a combined therapy. Additionally, this model can be used in studies on the influence of TNF on metastasis of tumor cells.

Acknowledgment: This research was supported by grants Nos. 6 P207 12106 and 3 P04B 01212 from the State Committee for Scientific Research, Poland.

\section{REFERENCES}

1. Abe Y., Sekiya S., Yamasita T. and Sendo F. (1990): Vascular hyperpermeability induced by tumor necrosis factor and its augmentation by IL- 1 and IFN- $\alpha$ is inhibited by selective depletion of neutrophils with a monoclonal antibody. J. Immunol., 145, 2902-2907.

2. Aggarwal B. B. and Natarajan K. (1996): Tumor necrosis factors. Development during the last decade. Eur. Cytokine Netw., 7, 93-124.

3. Asami T., Imai M., Tanaka Y., Hosaka Y., Kato K., Nakamura N., Horisawa Y., Ashida Y., Kanamori T., Nobuhara M. and Kurimoto M. (1989): In vivo antitumor mechanism of natural human tumor necrosis factor involving a $\mathrm{T}$ cell-mediated immunological route. Jpn. J. Cancer Res., 80, 1161-1164.

4. Asher A. L., Mulé J. J. and Rosenberg S. A. (1989): Recombinant human tumor necrosis factor mediates regression of a murine sarcoma in vivo via Lyt- $2^{+}$cells. Cancer Immunol. Immunother., 28, 153-156. 
5. Bachwich P. R., Chensue S. W., Larrick J. W. and Kunkel S. L. (1986): Tumor necrosis factor stimulates interleukin-1 and prostaglandin E2 production in resting macrophages. Biochem. Biophys. Res. Commun., 136, 94-101.

6. Becker J. C., Dummer R., Hartmann A. A., Burg G. and Schmidt R. E. (1991): Shedding of ICAM-1 from human melanoma cell lines induced by IFN-gamma and tumor necrosis factor-alpha. Functional consequences on cell-mediated cytotoxicity. J. Immunol., 147, 4398-4401.

7. Bhujwalla Z. M., Artemov D., Natarajan K., Solaiyappan M., Kollars P. and Kristjansen P. E. (2003): Reduction of vascular and permeable regions in solid tumors detected by macromolecular contrast magnetic resonance imaging after treatment with antiangiogenic agent TNP-470. Clin. Cancer Res., 9, 355-362.

8. Bigda J., Myśliwski A. and Dziadziuszko R. (1992): Bomirski Ab melanoma as a model of tumor-induced cachexia. In Freund M., Schmidt R. E., Link H. and Welte K. (eds.): Cytokines in hemopoiesis, oncology, and AIDS II. Springer Verlag, Berlin-Heidelberg, 405-408.

9. Bigda J., Myśliwski A., Myśliwska J., Witkowski J., Kmieć Z. and Bomirski A. (1989): Natural killer sensitivity of four Bomirski melanoma variants. Cancer Lett., 44, 67-72.

10. Bigda J., Myśliwski A., Sosnowska D., Romanowski P. and Bomirski A. (1991): Natural killer sensitivity of tumor cells isolated from primary and metastatic lesions of four Bomirski melanoma variants. Clin. Exp. Metastasis, 9, $57-65$.

11. Bomirski A., Słomiński A. and Bigda J. (1988): The natural history of a family of transplantable melanomas in hamsters. Cancer Metastasis Rev., 7, 95-118.

12. Carswell E. A., Old L. J., Kassel R. L., Green S., Fiore N. and Williamson B. (1975): An endotoxin-induced serum factor causes necrosis of tumors. Proc. Natl. Acad. Sci. USA, 72, 3666-3670.

13. Cubillos S., Scallon B., Feldmann M. and Taylor P. (1997): Effect of blocking TNF on IL-6 levels and metastasis in a B16-BL6 melanoma/mouse model. Anticancer Res., 17, 2207-2211.

14. Englaro W., Bahadoran P., Bertolotto C., Busca R., Derijard B., Livolsi A., Peyron J. F., Ortonne J. P. and Ballotti R. (1999): Tumor necrosis factor alpha-mediated inhibition of melanogenesis is dependent on nuclear factor kappa B activation. Oncogene, 18, 1553-1559.

15. Feinman R., Henriksen-DeStefano D., Tsujimoto M. and Vilèek J. (1987): Tumor necrosis factor is an important mediator of tumor cell killing by human monocytes. J. Immunol., 138, 635-640.

16. Folli S., Pélegrin A., Chalandon Y., Yao X., Buchegger F., Lienard D., Lejeune F. and Mach J. (1993): Tumor-necrosis factor can enhance radio-antibody uptake in human colon carcinome xenografts by increasing vascular permeability. Int. J. Cancer, 53, 829-836.

17. Grooten J., Goossens V., Vanhaesebroeck B. and Fiers W. (1993): Cell membrane permeabilization and cellular collapse, followed by loss of dehydrogenase activity: early events in tumor necrosis factor-induced cytotoxicity. Cytokine, 5, 546-555.

18. Grunhagen D. J., Brunstein F., Graveland W. J., van Geel A. N., de Wilt J. H. and Eggermont A. M. (2004): One hundred consecutive isolated limb perfusions with TNF-alpha and melphalan in melanoma patients with multiple in-transit metastases. Ann. Surg., 240, 939-948.

19. Hafner M., Orosz P., Krüger A. and Männel D. N. (1996):
TNF promotes metastasis by impairing natural killer cell activity. Int. J. Cancer, 66, 388-392.

20. Haranaka K., Carswell E. A., Williamson B. D., Prendergast J. S., Satomi N. and Old L. J. (1986): Purification, characterization, and antitumor activity of nonrecombinant mouse tumor necrosis factor. Proc. Natl. Acad. Sci. USA, 83, 3949-3953.

21. Haranaka K., Satomi N. and Sakurai A. (1984): Antitumor activity of murine tumor necrosis factor (TNF) against transplanted murine tumors and heterotransplanted human tumors in nude mice. Int. J. Cancer, 34, 263-267.

22. Havell E. A., Fiers W. and North R. J. (1988): The antitumor function of tumor necrosis factor (TNF) Therapeutic action of TNF against an established murine sarcoma is indirect, immunologically dependent, and limited by severe toxicity. J. Exp. Med., 167, 1067-1085.

23. Heicappell R., Naito S., Ichinose Y., Creasey A. A., Lin L. S. and Fidler I. J. (1987): Cytostatic and cytolytic effects of human recombinant tumor necrosis factor on human renal cell carcinoma cell lines derived from a single surgical specimen. J. Immunol., 138, 1634-1640.

24. Hieber U. and Heim M. E. (1994): Tumor necrosis factor for the treatment of malignancies Oncology, 51, 142-153.

25. Higashiyama A., Watanabe H., Okumura K. and Yagita H. (1996): Involvement of tumor necrosis factor alpha and very late activation antigen 4/vascular cell adhesion molecule 1 interaction in surgical-stress-enhanced experimental metastasis. Cancer Immunol. Immunother., 31, 231-236.

26. Higuchi M., Higashi N., Taki H. and Osawa T. (1990): Cytolytic mechanisms of activated macrophages: tumor necrosis factor and L-arginine-dependent mechanisms act synergistically as the major cytolytic mechanisms of activated macrophages. J. Immunol., 144, 1425-1431.

27. Hori A., Ikeyama S. and Sudo K. (1994): Suppression of cyclin D1 mRNA expression by the angiogenesis inhibitor TNP-470 (AGM-1470) in vascular endothelial cells. Biochem. Biophys. Res. Commun., 204, 1067-1073.

28. Ijzermans J. N., Scheringa M., van der Schelling G. P., Geerling R. A., Marquet R. L. and Jeekel J. (1992): Injection of recombinant tumor necrosis factor directly into liver metastases: an experimental and clinical approach. Clin. Exp. Metastasis, 10, 91-97.

29. Ingber D., Fujita T., Kishimoto S., Sudo K., Kanamaru T., Brem H. and Folkman J. (1990): Synthetic analogues of fumagillin that inhibit angiogenesis and suppress tumour growth. Nature, 384, 555-557.

30. Kawai T., Satomi N., Sato N., Sakurai A., Haranaka K., Goto T. and Suzuki M. (1987): Effects of tumor necrosis factor (TNF) on transplanted tumors induced by methylcholanthrene in mice A histopathologic study. Virchows Arch. B Cell Pathol. Incl. Mol. Pathol., 52, 489-500.

31. Kawai T., Satomi N., Sato N., Sakurai A., Haranaka K., Goto T. and Suzuki M. (1987): Necrotizing activity of tumor necrosis factor: histopathological investigation using Meth A sarcoma and granulation tissue. Virchows Arch. B Cell Pathol. Incl. Mol. Pathol., 53, 353-358.

32. Knippel E., Rychly J., Schulze H. A., Ringel B. and Krygier-Stojalowska A. (1988): Effect of recombinant human tumor necrosis factor on tumor and spleen in mice. Int. J. Cancer, 42, 395-399.

33. Koszałka P., Breza H. and Bigda J. (1998): Cloning, expression, purification of rat tumor necrosis factor and demonstration of its antitumor activity in Bomirski amelanotic melanoma. Neoplasma, 45, 162-168. 
34. Kozłowska K., Cichorek M. and Zarzeczna M. (2000): Implication of macrophage no and cytokine secretion in the cytotoxicity of transplantable melanomas as regards the progression of these tumors. Int. J. Immunopathol. Pharmacol., 13, 69-76.

35. Krönke M., Hensel G., Schlüter C., Scheurich P., Schütze S. and Pfizenmaier K. (1988): Tumor necrosis factor and lymphotoxin gene expression in human tumor cell lines. Cancer Res., 48, 5417-5421.

36. Kramer G., Steiner G. E., Sokol P., Handisurya A., Klingler H.C., Maier U., Foldy M. and Marberger M. (2001): Local intratumoral tumor necrosis factor-alpha and systemic IFN-alpha $2 \mathrm{~b}$ in patients with locally advanced prostate cancer. J. Interferon Cytokine Res., 21, 475-484.

37. Laster S. M., Wood J. G. and Gooding L. R. (1988): Tumor necrosis factor can induce both apoptotic and necrotic forms of cell lysis. J. Immunol., 141, 2629-2634.

38. Lewis M., Tartaglia L. A., Lee A., Bennett G. L., Rice G. C., Wong G. H., Chen E. Y. and Goeddel D. V. (1991): Cloning and expression of cDNAs for two distinct murine tumor necrosis factor receptors demonstrate one receptor is species specific. Proc. Natl. Acad. Sci. USA, 88, 2830-2834.

39. Männel D. N., Orosz P., Hafner M. and Falk W. (1994): Mechanisms involved in metastasis enhanced by inflammatory mediators. Circ. Shock, 44, 9-13.

40. MacEwan D. J. (2002): TNF receptor subtype signalling: differences and cellular consequences. Cell. Signal., 14, 477-492.

41. Melby P. C., Tyron V. V., Chandrasekar B. and Freeman G. L. (1998): Cloning of syrian hamster (Mesocricetus auratus) cytokine cDNAs and analysis of cytokine mRNA expression in experimental visceral leishmaniasis. Infect. Immun., 66, 2135-2142.

42. Moneo V., del Valle Guijarro M., Link W. and Carnero A. (2003): Overexpression of cyclin D1 inhibits TNF-induced growth arrest. J. Cell. Biochem., 89, 484-499.

43. Morikawa K. and Fidler I. J. (1989): Heterogeneous response of human colon cancer cells to the cytostatic and cytotoxic effects of recombinant human cytokines: interferon-alpha, interferon-gamma, tumor necrosis factor, and interleukin-1. J. Biol. Response Mod., 8, 206-218.

44. Mosmann T. (1983): Rapid colorimetric assay for cellular growth and survival: application to proliferation and cytotoxicity assays. J. Immunol. Methods, 65, 55-63.

45. Myśliwski A., Bigda J., Myśliwska J., Witkowski J. and Sosnowska D. (1995): Changes of natural killer cytotoxic activity and natural killer sensitivity during growth of Bomirski melanotic (Ma) and amelanotic ( $\mathrm{Ab})$ melanomas. Neoplasma, 42, 15-19.

46. Myśliwski A., Koszalka P., Bigda J. and Szmit E. (2002): Complete remission of Bomirski Ab amelanotic melanoma in hamsters treated with the angiogenesis inhibitor TNP-470. Neoplasma, 49, 319-322.

47. Myśliwski A., Szmit E., Szatkowski D. and Sosnowska D. (1997): Suppression of growth of Bomirski Ab melanoma and its metastasis in hamsters by angiogenesis inhibitor TNP-470. Anticancer Res., 17, 1-3.

48. Nawroth P., Handley D., Matsueda G., De Waal R., Gerlach H., Blohm D., Esmon C. T. and Stern D. (1988): Tumor necrosis factor/cachectin-induced intravascular fibrin formation in Meth A fibrosarcomas. J. Exp. Med., 168, 637-647.
49. Nooijen P. T., Manusama E. R., Eggermont A. M., Schalkwijk L., Marquet R. L., De Waal R. M. and Ruiter D. J. (1996): Synergistic effects of TNF-alpha and melphalan in an isolated limb perfusion model of rat sarcoma: a histopathological, immunohistochemical and electron microscopical study. Br. J. Cancer, 74, 1908-1915.

50. North R. J. and Havell E. A. (1988): The antitumor function of tumor necrosis factor (TNF) Analysis of the role of endogenous TNF in endotoxin-induced hemorrhagic necrosis and regression of an established sarcoma. J. Exp. Med., 167, 1086-1099.

51. Oettgen H. F., Carswell E. A., Kassel R. L., Fiore N., Williamson B., Hoffmann M. K., Haranaka K. and Old L. J. (1980): Endotoxin-induced tumor necrosis factor. Recent Results Cancer Res., 75, 207-212.

52. Okahara H., Yagita H., Miyake K. and Okumura K. (1994): Involvement of very late activation antigen 4 (VLA-4) and vascular cell adhesion molecule 1 (VCAM-1) in tumor necrosis factor alpha enhancement of experimental metastasis. Cancer Res., 54, 3233-3236.

53. Old L. J. (1985): Tumor necrosis factor (TNF). Science, 230, 630-632.

54. Østensen M. E., Thiele D. L. and Lipsky P. E. (1987): Tumor necrosis factor-alpha enhances cytolytic activity of human natural killer cells. J. Immunol., 138, 4185-4191.

55. Pagliacci M. C., Fumi G., Migliorati G., Grignani F., Riccardi C. and Nicoletti I. (1993): Cytostatic and cytotoxic effects of tumor necrosis factor alpha on MCF-7 human breast tumor cells are differently inhibited by glucocorticoid hormones. Lymphokine Cytokine Res., 12, 439-447.

56. Parhar R. S. and Lala P. K. (1985): Changes in the host natural killer cell population in mice during tumor development 2. The mechanism of suppression of NK activity. Cell. Immunol., 93, 265-279.

57. Poehlein C. H., Hu H., Yamada J., Assmann I., Alvord W. G., Urba W. J. and Fox B. A. (2003): TNF plays an essential role in tumor regression after adoptive transfer of perforin/IFN- $\gamma$ double knockout effector T cells. J. Immunol., 170, 2004-2013.

58. Rice G. C., Kramer S. M., Figari I. S., Ranges G. E. and Palladino M. A. (1990): Tumor necrosis factor-alpha: a species-specific cytokine? In Bonavida B. and Granger G. (eds.): Structure, mechanism of action, role in disease and therapy. Karger, Basel, 87-93.

59. Rychly J., Knippel E., Krygier-Stojalowska A., Nizze H., Kuchno M. and Kraeft S. (1990): DNA cytometric and histologic findings in mouse tumors (BP and S 180) with different response to treatment with tumor necrosis factor. Acta Oncol., 29, 47-51.

60. Schweigerer L., Malerstein B. and Gospodarowicz D. (1987): Tumor necrosis factor inhibits the proliferation of cultured capillary endothelial cells. Biophys. Res. Commun., 143, 997-1004.

61. Selgado A., Boveda J.L., Monasterio J., Segura R.M., Mourelle M., Gomez-Jimenez J. and Peracaula R. (1994): Inflammatory mediators and their influence on haemostasis. Haemostasis, 24, 132-138.

62. Smith R. A. and Baglioni C. (1987): The active form of tumor necrosis factor is a trimer. J. Biol. Chem., 262, 6951-6954.

63. Sugarman B. J., Aggarwal B. B., Hass P. E., Figari I. S., Palladino M. A. and Shepard H. M. (1985): Recombinant human tumor necrosis factor- $\alpha$ : effects on proliferation of normal and transformed cells in vitro. Science, 230, 943-945. 
64. Sugarman B. J., Lewis G. D., Eesalu T. E., Aggarwal B. B. and Shephard M. H. (1987): Effects of growth factors on the antiproliferative activity of tumor necrosis factor. Cancer Res., 47, 780-706.

65. Tomazic V. J., Farha M., Loftus A. and Elias E. G. (1988): Anti-tumor activity of recombinant tumor necrosis factor on mouse fibrosarcoma in vivo and in vitro. J. Immunol., 140, 4056-4061.

66. Tsujimoto M., Yokota S., Vilèek J. and Weissmann G. (1986): Tumor necrosis factor provokes superoxide anion generation from neutrophils. Biochem. Biophys. Res. Commun., 137, 1094-1100.

67. Vánky F., Wang P., Patarroyo M. and Klein E. (1990): Expression of the adhesion molecule ICAM-1 and major histocompatibility complex class I antigens on human tumor cells is required for their interaction with autologous lymphocytes in vitro. Cancer Immunol. Immunother., 31, 19-27.

68. van der Poll T. and Lowry S. F. (1995): Tumor necrosis factor in sepsis: mediator of multiple organ failure or essential part of host defense? Shock, 3, 1-12.
69. Voth R., Rossol S., Gallati H., Pracht I., Laubenstein H. P., Hess G., Müller W. E., Schröder H. C., Jochum C. and Meyer zum Büschenfelde K. H. (1988): In vivo and in vitro induction of natural killer cells by cloned human tumor necrosis factor. Cancer Immunol. Immunother., 27, 128-132.

70. Wallach D. (1984): Preparations of lymphotoxin induce resistance to their own cytotoxic effect. J. Immunol., 132, 2464-2469.

71. Webb D. S., Mostowski H. S. and Gerrard T. L. (1991): Cytokine-induced enhancement of ICAM-1 expression results in increased vulnerability of tumor cells to monocyte-mediated lysis. J. Immunol., 146, 3682-3686.

72. Wedlock D. N., Aldwell F. E. and Buddle B. M. (1996): Molecular cloning and characterization of tumour necrosis factor alpha (TNF- $\alpha$ ) from the Australian common brushtail possum, Trichosurus vulpecula. Immunol. Cell Biol., 74, $151-158$

73. Zhang Y., Griffith E. C., Sage J., Jacks T. and Liu J. O. (2000): Cell cycle inhibition by the anti-angiogenic agent TNP-470 is mediated by $\mathrm{p} 53$ and p21 ${ }^{\mathrm{WAF} 1 / \mathrm{CIP} 1}$. Proc. Natl. Acad. Sci. USA, 97, 6427-6432. 
